\title{
SEIS VOCES DE ORIGEN ÁRABE
}

Cualquier estudio que, hoy en día, pretenda establecer nuevas etimologías para palabras ya recogidas en el Diccionario Etimológico $(D C E C H)^{*}$, lo hará, las más de las veces, apoyándose en una documen-

* Se emplean las siguientes abreviaturas:

alEA $=$ M. Alvar, A. Llorente y G. Salvador, Atlas Lingüistico y Etnogrdfico de Andalucía, Universidad de Granada, C.S.I.C., 1961.

ALEANR $=$ M. Alvar y col., Atlas Lingüistico y Etnografico de Aragón, Navarra y La Rioja, Dept. de Geografía Lingüística, Institución Fernando el Católico de la Excma. Diputación Provincial de Zaragoza, C.S.I.C., Madrid, 1979-1982.

Autoridades = Real Academia Española, Diccionario de la Lengua Castellana, Madrid, 1726-1739.

Covarrubias = Sebastian de Covarrubias, Tesoro de la Lengua Castellana o Española, 1611. (Re-editado por Turner, Madrid, 1979.)

DCEC = JoAN COROMINAS, Diccionario Critico Etimológico de la Lengua Castellana, 4 volúmenes, Gredos, Madrid, 1974. (1.* ed., 1954.)

DCECH = J. Corominas y J. A. Pascual, Diccionario Crítico Etimológico Castellano e Hispánico, 6 volúmenes, Gredos, Madrid, 1980. (Es una nueva edición del DCEC, puesta al día por el segundo autor; en la fecha de concluir este artículo aún no ha salido el último volumen.)

Eguilaz = L. DE Eguflaz Y Yanguas, Glosario Etimológico de las Palabras Españolas... de Origen Oriental, Granada, 1886.

Glossaire = R. Dozy y W. H. EngelmanN, Glossaire des Mots Espagnols et Portugais Dérivés de l'Arabe, Leiden, 1869.

P. de Alcalá = PEDRo DE ALCALA, Arte para ligeramente saber la lengua aráviga y Vocabulista arávigo en lengua castellana, 1505. (Ed. facsímil, Nueva York, 1928.)

Voc. $=$ C. Schiaparelli (ed.), Vocabulista in Arabico (sopra un codice della Biblioteca Riccardiana di Firenze), Florencia, 1871. (Las voces recogidas en este léxico del árabe hispánico corresponden especialmente a la zona levantina de la Península, y al siglo xIII). 
tación mejorada que aclare puntos oscuros de la historia del vocablo, oponiéndose decisivamente a la teoría previamente aceptada y desvelando nuevas pistas hacia el verdadero origen. $Y$ aunque el investigador se siente consciente de que otros descubrimientos posteriores puedan debilitar o incluso invalidar sus hipótesis, es, sin embargo, cierto que la progresiva acumulación de material linguístico hace que tal desenlace sea cada vez menos probable. Así, en este trabajo, la aportación documental ha sido crucial para la demostración de cinco de las seis etimologías presentadas. Un conocimiento de la historia del pueblo minero murciano de Mazarrón es la clave para explicar la creación de la voz almazarrón «almagre»; comprendemos mejor cómo almenara llegó a emplearse en el sentido de "compuerta" si tenemos en cuenta unos sinónimos romances corrientes en el lenguaje de la huerta de Murcia; los datos de los Atlas Linguiísticos de Aragón y Andalucía indican que debemos rechazar la tradicional etimología aragonesa de bardomera y ayudan en la búsqueda de otra más idónea; en el caso de la operación de riego rafa, la documentación medieval revela la inexactitud de la definición que recogen los diccionarios, lo cual invalida las etimologías que se basaban en ella; y en cuanto a marmotera, la única de las seis voces tratadas aquí que no figura en el $D C E C H$, todos los datos son, en cierto modo, nuevos. En lo que se refiere a tragacete, el propuesto étimo árabe fue hallado mediante una "disección» sistemática que tenía en cuenta las reglas de formación morfológica de esta lengua, mientras que una cita nueva ayuda a aclarar la presencia de este vocablo en el vasco.

\section{ALMAZARRON}

La voz almazarrón "un tipo de almagre u ocre rojo empleado en la pintura y para teñir» no aparece en ningún diccionario anterior al de Autoridades (Tomo I, 1726), donde se da como equivalente de «almagre», con el apoyo documental de una entrada de la Pragmática de tassas del año de 1680: «Cada libra de almazarrón no pueda passar de veinte y quatro maravedis» (fol. 16). La única etimología que se ha propuesto hasta ahora para este vocablo - pasado por alto por Engelmann y Dozy en su Glossaire - es la de Eguílaz, quien lo considera un aumentativo castellano del árabe miṣr «arcilla roja», término que se halla en el diccionario árabe de Freytag '. El hecho, apuntado por Eguílaz, de que otros

1 L. Eguthaz, op. cit., pág. 118. 
diccionarios árabes dan para esta voz el significado de «tierra roja con la cual se señala» encaja perfectamente con lo que dice Covarrubias (1611) con referencia al almagre:

Es una tierra colorada con que los asserradores y carpinteros suelen señalar las líneas por donde han de asserrar el madero o tabla, desatándola en agua y tiñendo en ella una cuerda que, estendida de estremo a estremo del madero, la golpean, levantándola con los dedos, y queda señalada en él, por la qual se rigen al asscrrar ${ }^{2}$.

De esta manera, la equivalencia semántica entre el árabe miṣr "almagre» y el castellano almazarrón 'almagre' queda fuera de duda. No obstante, la etimología de Eguílaz, aceptada por Corominas en su DCEC y mantenida en la última edición $(D C E C H)$, deja sin resolver dos cuestiones: a) por qué la primera documentación es tan tardía (1680) cuando su homónimo almagre aparece ya en los textos del siglo XIII; y b) cómo se pasó del árabe al-mișr a la forma romance almazarrón, pues a primera vista no es fácil justificar la presencia de la terminación, que se describe, algo lacónicamente, como un "aumentativo castellano».

La respuesta a la primera de estas preguntas, y quizás la de la segunda también, se ha de buscar en la historia minera de la villa murciana de Mazarrón, estrechamente vinculada a la extracción del alumbre y del almagre ${ }^{3}$. Durante los primeros dos siglos después de la Reconquista del Reino de Murcia (s. XIII), el lugar, que hasta el siglo XVII o XviII se llamaba Almaçarrón o El Almaçarrón ${ }^{4}$, carecía de una población estable: aquellos campos fronterizos eran demasiado peligrosos para ser habitados permanentemente, abiertos a las constantes incursiones musulmanas, tanto por tierra como por mar, en búsqueda de ricos despojos de cautivos y ganado ${ }^{5}$. No fue hasta la segunda mitad del siglo $\mathrm{xV}$, cuando el peligro de estas razzias granadinas aminoró, y se comenzaron a aprovechar los ricos yacimientos de alumbre y almagre que tanta reputación llegaron a adquirir en otro tiempo. Nos informa Madoz que la explotación de las ricas minas de alumbre empezó por privilegio de

2 Sebastian de Covarrubias, Tesoro de la Lengua Castellana o Española, 1611; ed. Turner, Madrid, 1979, pág. 93.

3 Parece que Corominas ya sospechaba alguna relación de este tipo: vide DCEC y DCECH s.v. almazarrón.

4 Ver la documentación medieval reunida por C. Hernandez CarRasco, «El Arabe en la Toponimia Murciana», Anales de la Univ. de Murcia, Fil. y Letras, vol. XXXIV (1975-76), pág. 240.

5 Por ejemplo, en las Actas Capitulares del Concejo de Murcia de 20-IX-1474 se lee: «andaron dar su carta...a Diego Martines de Petrel que catiuo en el Almaçarron, guardando ganado, puede auer quatro años; e fa estado quatro ańos en catiuo en Malaga; e costo de rescate veinte e seys mill marauedis». 
Enrique IV, concedido a los marqueses de Villena y de Vélez, en 24 de mayo de 1462. Las minas se establecieron en el cerro de San Cristóbal, en cuya falda noroeste se alzaron los primeros edificios de la villa, destinados a la conservación y resguardo de las oficinas, enseres, herramientas y domicilios de los fabricantes y jornaleros que sucesivamente fueron aumentando la población, en términos que a fines de dicho siglo mereció se le concediera el título, por real privilegio, de Villa de las Casas de los Alumbres de Mazarrón ${ }^{6}$. La producción de alumbre alcanzó su mayor auge entre los años de 1485-1550, cuando se solían elaborar más de 40.000 quintales de alumbre cada año, consumiéndose la cuarta parte en los tintes y curtidos nacionales, y exportándose el resto a Inglaterra, Flandes, Holanda y Alemania. El decaimiento de esta industria en la segunda mitad del siglo xvi se debió a muchas causas, entre ellas el descubrimiento de innumerables minas semejantes en los mencionados países, y en el Rosellón, desde cuyo punto se comunicó a Aragón. Como resultado, la producción descendió hasta tan solamente 3.000 quintales/año en 1588, y los trabajos se paralizaron del todo a partir de 1592.

Pero en estos años, los referidos Marqueses se dieron cuenta de una nueva riqueza derivada de la anterior fabricación de alumbre: el almagre, que durante un siglo se había ido acumulando como residuo o sedimento que se posaba en los trullos o grandes depósitos de lejías del alumbre, antes de evaporarlas para reducirlas a un estado de cristalización. Durante todo el siglo xviI y parte del xviII, los Marqueses explotaron la venta de este nuevo artículo de general consumo en la Península, concurriendo a comprar el dicho almagre la Real Hacienda para sus arsenales, y especialmente para dar frescura y suavidad al famoso tabaco colorado de Sevilla?

Volviendo ahora al vocablo almazarrón 'almagre', nos encontramos ya en situación de arrojar un poco de luz sobre la historia de su creación. Sabemos que la venta del almagre del Almazarrón se inició hacia el año 1600 y continuó durante todo este siglo y parte del siguiente, tratándose de un almagre de calidad especial. Teniendo en cuenta que la primera documentación de la voz almazarrón es de 1680 , cuando la

6 No sé si en el documento original el topónimo aparecería sin el artículo árabe, pero en caso afirmativo se tratará de una versión paralela y «oficial» del nombre del pueblo, empleada sobre todo en la corte. Así, en una carta real de 1428, referente a la cria de halcones, se le: «en las yslas de las mares de Cartagena e del Maçarron e de las Aguilas» (Arch. Mun. de Murcia, Cartulario Real de 1411-29, fol. 192 recto).

7 MaDoz, Diccionario Geográfico, s.v. Mazarrón. 
comercialización del mencionado almagre estaba en su cúspide, es preciso concluir que el almazarrón recibió su nombre del nombre del lugar de donde procedía, mediante elipsis de la expresión almagre de Almazarrón, proceso semántico muy común.

Buscar el origen del topónimo (Al)Mazarrón no es competencia de un estudio lexicológico, pero podemos hacer algunas observaciones al respecto. No se puede excluir la posibilidad de alguna relación con la raíz árabe ya aludida: al-miṣr 'el almagre', aunque habría que rechazar definitivamente la hipótesis de que la terminación -ón o -arrón sea simplemente un "aumentativo castellano". A pesar de que haya quedado demostrado que el topónimo ya existía antes de la instalación de las fábricas mencionadas, los mismos yacimientos bien pudieron haberse explotado en la época árabe ${ }^{8}$. Entonces, en lugar de derivar el topónimo directamente de al-miṣr, lo cual sería imposible, habría que suponer la existencia en el árabe regional de un derivado *al-mașrūn 'la almagrera', de formación morfológica similar al árabe levantino al-gayụūn 'el de las pequeñas cantidades, algaidón, cigoñal para sacar agua', derivado de gayḍ 'pequeña cantidad' '. Este nombre árabe pasaría al castellano bajo la forma *Almaçarón, que fácilmente se convertiría en Almaçarrón bajo la influencia del sufijo -arrón ${ }^{10}$.

\section{ALMENARA}

Los distintos significados que posee, o ha poseído, la voz castellana y dialectal almenara suelen ser agrupados en dos categorías conceptuales: I) los relacionados con la luz o el fuego, y II) los relacionados con la irrigación. El DCECH sólo da para almenara $I$ el significado de «señal que se hace con fuego en lugar elevado", pero a éste habría que añadir «candelero de muchas mechas» $y$ "asiento de hierro que sujeta

8 Ver las observaciones a este efecto de J. Vallvé en Al-Qanțara, I, pág. 217 y Al-Andalus, XXXVII, fasc. 1, pág. 172.

9 Ver: ARnald SteIGER, «Toponimia Arabe en Murcia», Murgetana, núm. 1, Murcia, 1958, pág. 13. Esta voz árabe no figura más que en el Voc.

10 Respecto al origen de este topónimo, C. HernánDez Carrasco (op. cit., pág. 240) considera varias posibilidades, ninguna de las cuales se impone decisivamente. La solución que ella prefiere, marsà al-rūm «el puerto de los romanos o bizantinos», tiene las dificultades: a) la villa está a siete kilómetros del mar; b) esperariamos * Marçarrón en la documentación antigua: no es admisible generalizar diciendo que «la palabra marsd parece que se romancea con la forma Maza»; y c) el artículo árabe de la forma antigua Almaçarrón no se explica. 
teas para alumbrarse»; ambos significados figuran en el Diccionario de la Academia y en el de Autoridades. Como ya señaló Dozy (Glossaire, pág. 163), todas estas acepciones tienen correspondencia entre los significados que se documentan para la voz árabe al-manāra (lit. "el lugar del fuego, o de la luz»), y no existe ningún impedimento para aceptar esta etimología.

En cuanto a almenara II, el Diccionario de Autoridades indica dos significados bastante diferenciados: «zanja por donde se conduce otra vez al río el agua que sobra en las acequias..», y «la abertura cerrada con una compuerta entre dos piedras, para despedir el agua que sobra en las acequias, o para distribuir en ellas la que está rebalsada en un pantano o cosa semejante». Ambas voces tenían uso en Aragón ${ }^{11}$. La etimología propuesta por Dozy y recogida en el $D C E C H$ es aceptable para el primero de estos significados: al-manhar «el canal». En rigor habría que suponer la existencia de una variante *al-manhara en el árabe regional, con el mismo significado que al-manhar, cuya terminación -a sería la que forma nombres de unidad en esta lengua. Puesto que al-manār y al-manāra funcionaban como sinónimos (ver Dozy, loc. cit.), sería difícil oponernos a una relación similar entre al-manhar y *al-manhara.

Sin embargo, el segundo significado: "abertura en el muro de una presa o en el costado de una acequia...» está bastante alejado de la idea "canal", y, en el $D C E C H$, no queda muy claro si los autores también desean sacar el vocablo en esta acepción de la misma raíz árabe almanhar, o acaso de almenara «zanja..» con desarrollo semántico posterior dentro del romance, o si, por el contrario, se han abstenido de emitir un juicio; de hecho, no mencionan explícitamente este significado, si bien citan algunos topónimos de la zona catalanoaragonesa que reflejan el empleo del vocablo en dicho sentido. Por nuestra parte, en vista de lo difícil del paso semántico de "canal, zanja» a "abertura, orificio", creemos que es más oportuno adoptar otra etimología para almenara en esta última acepción.

Según el Vocabulario del Dialecto Murciano, de Justo García Soriano, se emplea la voz lumbrera en esta región para designar «el umbral en la boquera de un cauce" ${ }^{12}$. Con más exactitud se trataría de un

11 Según el ALEANR almenara se emplea en La Codoñera (Teruel) como «desagüe para la presa» (mapa 89) y en Arañuel, Segorbe y Bejís (Castellón) como *tablacho, compuerta» (mapa 91).

12 Vocabulario del Dialecto Murciano, Madrid, 1932, pág. 75. No he podido confirmar que se siga empleando este término hoy en la huerta de Murcia. La cita documental en que se apoya García Soriano parece referirse a un topónimo ( $\alpha . . . n i$ hagan rafa en la acequia mayor de las lumbreras abajow. Ordenanzas de Murcia, página 155, 1695). Además, no aparece una sola vez en las Ordenanzas y Costum- 
'orificio en el costado de una acequia, o en un muro, para dar paso al agua'. Tal sentido se desprende, por ejemplo, de la siguiente cita referente a una acequia que penetraba en el recinto amurallado de la ciudad de Lorca:

Dichas aguas que por una lumbrera muy capaz pueden servir para beneficio de la Ciudad, dentro de la muralla en la Puerta Nueva, a corta distancia toman luego la salida por otra mina o bóveda ${ }^{13}$.

Estamos ante una aplicación especial del castellano medieval lumbrera "ventana pequeña en alto que sirve tan solamente de dar luz" (Covarrubias). No resulta difícil comprender cómo se llegó a comparar una ventana de reducidas dimensiones por la que entraba un haz de luz, con un agujero por donde salía un chorro de agua. Y si aún dudáramos, el símil se vuelve a encontrar en el habla huertana actual, donde la palabra ventana ha adquirido el mismo significado:

Art. 53. En los quijeros de las acequias nadie puede abrir portillos, y los que inmediatamente tienen riego de ellas deben tener sus ventanas o tomas hechas de piedra o ladrillo.

Art. 145. Cuando se acaba de regar debe taparse bien la ventana de la acequia, dejando abierto el portillo del bancal para que entre en el toda el agua.

El refrán dice: riego concluido tapa la ventana y deja el portillo ${ }^{14}$.

bres de la Huerta de Murcia, Compiladas y Comentadas por Pedro Díaz Cassou (Madrid, 1889; re-editado por la Junta de Hacendados de la Huerta de Murcia, Murcia, 1971, y en venta en el Ayuntamiento), que hace un análisis profundo de todo el sistema de regadíos de Murcia y de su historia. La única documentación que tengo del uso de lumbrera como apelativo y con el significado que nos interesa aquí data del siglo xv:

"Quando se atajen las açequias por el mes de agosto...se monden o linpien las lunbreras del regueron que viene por la calle de la Moreria, e abran la boquera del, segund ante solia estar, e que se parta la meytad del agua a Sant Antolin e la otra meytad a San Miguell, por que las cavas enxaguen e esten linpias, e que las dichas lunbreras se monden a costa de las dichas dos collaçiones» (A.C.: 7-5-1476).

Parece probable, por otra parte, que el vocablo siguió empleándose durante más tiempo con esta acepción en Lorca, de lo cual da testimonio tanto el pasaje de Fray Pedro Morote que cito más abajo, como este extracto de las Ordenanzas de Lorca (Granada, 1713):

«Mandamos que qualquier vezino de esta Ciudad que abriere, o sacare agua, de alguna de las lumbreras de la Fuente del Oro, tenga de pena seiscientos maravedis» (pág. 113; una reproducción de la 1:" edición ha aparecido: ed. Academia Alfonso X El Sabio, Murcia, 1983).

13 Fray Pedro Morote, Antigüedad y Blasones de la Ciudad de Lorca, Murcia, 1741, pág. 57.

14 Ordenanzas y Costumbres..., 1889 (ver nuestra nota 2), págs. 66 y 118. 
Volvamos ahora a la voz almenara, cuya acepción aragonesa de "abertura...» coincide plenamente con la que adquirieron lumbrera y ventana en el lenguaje huertano de Murcia. Como ya se ha mencionado, la forma al-manāra ostentaba en el árabe hispánico, entre otros significados, los de «asiento de hierro que sujeta teas para alumbrarse» y «candelero de muchas mechas». En Egipto, al-manwar tiene prácticamente el mismo sentido: «longue perche avec plusieurs lampes attachées au bout supérieur" ${ }^{15}$. Esto no debe de sorprendernos mucho porque, en realidad, manwar y manār(a) son formas de valor morfológico similar, derivadas de una misma raíz. Pero lo que es verdaderamente interesante para nuestro caso es el hecho de que al-manwar también significa "soupirail, ouverture pour éclairer, aérer un souterrain» ${ }^{16}$, de modo que hay motivos para creer que en España al-manāra tuvo este mismo significado. Entonces, el aragonés almenara 'abertura para dar paso al agua' debe proceder de al-manāra 'lucerna, tragaluz' mediante el mismo proceso semántico que detectamos para lumbrera y ventana en Murcia, mientras que la existencia de la acepción 'abertura...' de la voz almenara quizás constituye nuestra mejor prueba de que al-manāra realmente significó 'lucerna' en el hispanoárabe. Por otra parte, dado que almenara no parece haberse empleado en el sentido de 'lucerna, tragaluz' en romance, hay que concluir que el desdoblamiento del significado ya había sucedido dentro del árabe, lo cual nos permite aventurar la hipótesis de que la aparición de la acepción especial de lumbrera, y más tarde de ventana, en Murcia sea atribuible a la influencia árabe. Sabido es que los mudéjares desempeñaron un papel fundamental en el uso y mantenimiento de las acequias murcianas en la Edad Media. Apenas nos habría de sorprender, por lo tanto, que conociendo el castellano lumbrera en su significado 'lucerna', lo emplearan también en el otro, llevando la equivalencia semántica más allá de sus antiguos límites.

\section{BARDOMERA Y MARMOTERA}

Se emplea la voz bardomera en el murciano actual para referirse a la «broza y suciedad que traen los ríos sobre su corriente en las avenidas» ${ }^{17}$. En Orihuela, bardomeras son las «brozas y otros desperdicios

15 R. Dozy, Supplément aux Dictionnaires Arabes, Leiden, 1881 (ed. facsímil, Beirut, 1968), tomo II, pág. 744.

16 Ibidem.

17 J. Garcta Soriano, Vocabulario del Dialecto Murciano, Madrid, 1932, pág. 16. 
que obstruyen el acueducto" ${ }^{18}$, y en Lorca el vocablo tiene este mismo sentido, refiriéndose específicamente a los materiales que quedan depositados en las acequias tras una crecida del río o de las ramblas. Según el Atlas Lingüístico y Etnográfico de Andalucia (ALEA), la palabra también tiene uso en muchos pueblos almerienses, especialmente los más cercanos a la frontera con Murcia. En Oria, por ejemplo, significa "broza y tierra arrastradas por el agua» ${ }^{19}$, mientras que en diez puntos de la provincia la expresión quitar la bardomera significa «desbrozar para que corra el agua ${ }^{20}$. Por otra parte, en ocho lugares de la misma provincia el nombre dado a la obstrucción en el cauce se ha llegado a aplicar al efecto que causa, llamándose bardomera al «agua de riego estancada accidentalmente» ${ }^{21}$. Finalmente, en Pulpí el término se refiere a un obstáculo colocado deliberadamente en la acequia, sin la mediación de ningún fenómeno natural: «montón de tierra o barro que se pone en una reguera para cambiar una dirección del agua» 22. García Soriano indica que nuestra voz también tiene uso en el aragonés ${ }^{23}$, pero no aparece en ninguno de los mapas correspondientes del Atlas Lingüistico y Etnográfico de Aragón, Navarra y Rioja (ALEANR) ${ }^{24}, \mathrm{ni}$ tampoco en los estudios de hablas locales que he podido consultar, de modo que hay que duclar de la certeza de esta afirmación mientras no se demuestre lo contrario, sobre todo teniendo en cuenta los datos acerca de la forma bardoma que reunimos más abajo. Parece, por lo demás, que el vocablo es de creación bastante reciente; no conozco documentación anterior a este siglo y la cita que aporta García Soriano ("Un río enfangado ... de espumas y bardomera») procede de un libro escrito en 1921 por el novelista Gabriel Miró Ferrer, que nació en Alicante pero que pasó una buena parte de su juventud en Orihuela, donde es probable que aprendiera la palabra.

Pero si, a pesar de su considerable difusión geográfica, el murcianismo bardomera resulta ser una formación relativamente moderna, no se puede decir lo mismo del substantivo del cual se deriva, bardoma,

18 J. Guillén Garcta, «El Habla de Orihuela», Instituto de Estudios Alicantinos, serie I, núm. 15, Alicante, 1974, pág. 133.

19 ALEA, mapa 90.

20 ALEA, mapa 91: en Lúcar, Contador, La Perulera («quitar las bardomeras»), Alcóntar, Bacares («limpiar la bardomera»), Gérgal, Cantoria, Palomares (cerca de Vera), Gafarillos y Carboneras.

21 ALEA, mapa 90: en Lúcar, Contador, Alcóntar, Gérgal, Vera, Palomares, Gafarillos y Tabernas. En Lúcar y Carboneras se dijo baldomera.

22 ALEA, mapa 85.

23 Loc. cit. en la nota 1.

24 ALEANR, mapas 94 («Desbrozar para que corra el agua») y 1375-1381 («Barro» etcétera). 
cuyo arraigo en estas tierras está confirmado a través de la documentación, donde se emplea con el mismo significado que bardomera, según se desprende, por ejemplo, de la siguiente cita de las Actas Capitulares del Concejo de Murcia del año de 1481:

fueron a sacar unas bardomas del Alventosa, que echo la cresçida del rio 25.

El verbo bardomarse 'llenarse la acequia de bardomas' figura ya en un texto de 1275 , referente a Orihuela, donde se fijan las obligaciones del sobreacequiero y diversas disposiciones relativas al uso y mantenimiento de las acequias:

Et las paradas se fagan como en tienpo de moros et non en otra manera, asi que non metan y cieno nin lodo, porque las cequias se bardome 26 .

Tratándose de nuestra documentación más antigua del vocablo, es interesante que en este caso las bardomas no procedían de una crecida del río, sino de paradas mal construidas en las acequias, y que, además, se habla de cieno y lodo, y no de broza. El verbo y algunos derivados siguen empleándose hoy en Orihuela ${ }^{27}$. Fuera del ámbito murciano la voz bardoma se asoma en diversos lugares y épocas. En el pueblo almeriense de Paterna del Río, situado junto a la frontera con Granada en los comienzos de las Alpujarras, quitar la bardoma tiene el mismo significado que quitar la bardomera en los lugares señalados más arriba ${ }^{28}$. El Diccionari Català-Valencià-Balear de Alcover y Moll, recoge dos testimonios: en un documento del año 1439 del Archivo General del Reino de Valencia figura la expresión "Molta bardoma», pero no dan ninguna indicación de significado ni contexto; y en el pueblo de Tremp, bardoma es la «lozanía o fuerza con la que crece una planta», donde posiblemente se trata de una palabra de otro origen. Según la misma fuente, también hubo un derivado bardomàs, equivalente de un castellano bardomazo, que se halla en un documento de 1450: "Dos bardomasos de mescla", pero, de nuevo, a falta de cualquier información en torno al contexto de la cita, es difícil aprovechar este dato.

25 Archivo Municipal de Murcia, sesión de 2-XI-1481.

26 J. TORRes Fontes, Colección de Documentos para la Historia del Reino de Murcia, III, Fueros y Privilegios de Alfonso X el Sabio al Reino de Murcia, Academia Alfonso X el Sabio, Murcia, 1973, pág. 149. No se conserva el original, lo cual explica la falta de claridad en las últimas palabras.

27 J. Guillén Garcta, loc. cit.: «los fardomaores..limpian el cauce de bardomeras..; cuando existen en abundancia, se dice que la sequia o la sarbe s'ha bardomao y hay que esfardomarla es decir limpiarla». En este dialecto la aspiración de la $s$ implosiva convierte en $f$ una $b$ siguiente.

28 ALEA, mapa 91. 
No obstante, quizás el testimonio más significativo, y al mismo tiempo más problemático, de su empleo fuera del territorio murciano, es su aparición en el Diccionario de Autoridades como "voz baxa usada en Aragón" donde significaría "Porquería, suciedád, lodo corrompido», y vendría del "Gascon Bardo, que significa lodo» ${ }^{29}$. En primer lugar es preciso contrastar con este aserto acerca de su empleo en el aragonés el hecho de que bardoma no figura en ninguno de los mapas del ALEANR en los cuales se podría esperar encontrarla, ni tampoco en los estudios de hablas locales. Ello puede tener dos explicaciones: (i) que se empleaba en algunas partes de Aragón en el siglo xvilI pero que se ha perdido totalmente hoy; o (ii) aunque no tenían datos concretos de su empleo en Aragón, los redactores del Diccionario, al recibir noticia de su uso en Murcia, supusieron que se trataba de una de las muchas voces que el murciano compartía con el aragonés, porque, dando por segura su procedencia de la palabra pirenaica bardo, era necesario que se hubiera empleado en Aragón antes de poder ser llevada a Murcia. Nuestra elección entre estas dos hipótesis dependerá en gran medida de la aceptabilidad de la etimología, adoptada por Corominas en su DCEC y mantenida en el DCECH, que saca bardoma de bardo. Si es así, entonces es forzoso que aquélla sea antigua voz aragonesa, pero si tienen etimologías radicalmente distintas no hay motivo por atribuir demasiado peso al testimonio del Diccionario de Autoridades. Antes de someter la citada etimología a escrutinio, consideremos la siguiente alternativa.

Si excluimos momentáneamente los datos del Diccionario de Autoridades por hallarse, en cierto modo, sub judice, y los del Diccionario de Alcover y Moll por ser confusos y probablemente debidos a una palabra distinta, entonces todas nuestras fuentes seguras, tanto para bardomera como para bardoma: a) proceden de la zona murciana-almeriense; y b) coinciden en indicar un significado de «broza $u$ otros materiales que han quedado depositados en los cauces de los ríos, ramblas o acequias, tras una crecida o por otras causas, y acaban impidiendo el libre paso del agua». Ahora, el verbo árabe radam quiere decir 'taponar, obstruir o cegar con tierra', y su participio pasado femenino

29 Los textos posteriores, como el Diccionario de Voces Aragonesas de J. BorAo (Zaragoza, 1859), que también traen bardoma como voz aragonesa, deben haber tomado sus datos directa o indirectamente del Diccionario de Autoridades, pues repiten su definición palabra por palabra. Incluso J. Garcta SORIano en su Vocabulario del Dialecto Murciano recoge esta misma definición aunque en la cita documental que aporta, procedente del mismo autor que citó para bardomera, el contexto demuestra que se trata de un sinónimo de esta última palabra: «El río iba somero...de bardomas» (loc. cit.).

LXV, $1.0^{\circ} \cdot 2 .^{\circ}-5$ 
mardūma es, por lo tanto, 'taponada, obstruida o cegada con tierra', lo cual constituye una excelente etimología para bardoma. El paso de $m$ - a $b$-se deberá a una disimilación entre las dos $m$ que tiene esta palabra árabe; es muy poco probable que la voz bardo 'barro' del alto aragonés haya influido en este cambio, a causa de la enorme separación geográfica entre las zonas donde se emplean estas dos palabras. Es un poco más difícil explicar por qué la $\bar{u}$ árabe pasaría al romance como $o$ sin estar en contacto directo con una consonante velarizadora, pero debemos recordar que en el árabe $/ \mathrm{u} / \mathrm{y} / \mathrm{o} /$ son meros alófonos de un solo fonema $U$, y la experiencia demuestra que las reglas de su distribución según el contexto consonántico no siempre se obedecían con rigor, o que en algunos casos pudo haber interferencia de otras palabras en el paso del árabe al romance ${ }^{30}$. La ausencia del artículo árabe, que casi siempre está presente en los arabismos murcianos, se explica porque la forma mardūma funcionaría como adjetivo en el árabe: se puede imaginar cómo un obrero mudéjar de las acequias, con un mínimo o nulo conocimiento del idioma de los cristianos, pocos años después de la reconquista de Murcia, diría, señalando un lugar donde la acequia estaba obstruida por barro o broza: "imardūma!", y el capataz, de habla romance, le ordena: «Pues, quita la imardoma/bardoma!». En tales situaciones el paso semántico del resultado ('acequia obstruida') a la causa ('broza y barro depositados en el cauce') sería casi inevitable, y muy parecido a lo que ha sucedido con el vocablo rafa (ver más abajo), donde el significado etimológico 'levantamiento del nivel del agua en un cauce' se ha convertido prácticamente en 'parada construida en la acequia con este fin'.

Volvamos ahora a la etimología que proponía derivar bardoma del alto aragonés bardo 'barro'. En vista de la idoneidad de la citada etimología árabe, tan natural en una voz murciana referente al regadío, creo que hay que descartar cualquier relación con bardo, a pesar del parecido semántico, por dos motivos: a) no tenemos ninguna evidencia de que jamás se haya empleado nuestro vocablo bardoma en la zona pirenaica donde se documenta el uso de bardo, condición imprescindible para dicha etimología; y b) no se explicaría el sufijo o terminación -óma, que nunca se ha empleado en la derivación de voces en el romance peninsular. La única salida racional sería proponer como étimo una forma *bárdoma con sufijo átono prerromano, que tendría buenas posibili-

30 Por ejemplo, qādūs ha dado tanto arcaduz como cadozo; de búnduqa procede albóndiga; de burnūs, albornoz; de fúnduq viene alhóndiga; de fústaq, alfónsigo; etcétera. 
dades de convertirse en bardóma en el aragonés, dada su documentada tendencia a trasladar el acento a la penúltima sílaba en los esdrújulos. Esto encajaría bien con el probable origen prerromano de bardo y barro. No obstante, a pesar de la gran variedad de sufijos átonos que logró reunir Menéndez Pidal en su conocido estudio ${ }^{31}$, no halló ningún caso de Łoma; de hecho, la vocal penúltima $o$ no es muy frecuente en este tipo de sufijo, y parece limitarse a los que contienen la consonante $l$, donde no se puede excluir una procedencia latina; la consonante $m$ siempre va precedida por la vocal a (la que predomina en todos los sufijos átonos de probable origen prerromano): cáñamo, páramo, préstamo, Uxăma (=Osma), Ledisăma (=Ledesma), etc. Así, pues, teniendo en cuenta todas estas dificultades, creo que la etimología árabe ha de considerarse segura.

Muy parecidas a bardoma y bardomera desde muchos puntos de vista son las voces marmota y marmotera, que se emplean con los mismos significados en zonas contiguas del extremo oriental de Andalucía. En Vélez Rubio, situado en la frontera noreste de la provincia de Almería, marmotera es "la broza que se lleva el agua por delante», y se dice que hace marmotera cuando el agua de riego queda estancada accidentalmente ${ }^{32}$, empleándose expresiones similares para representar este concepto en otros siete puntos del este de Jaén y Granada, y del norte de Almería (ver mapa) ${ }^{33}$. Por otra parte, «desbrozar para que corra el agua" se dice quitar la marmotera en cinco de los lugares encuestados de la misma comarca ${ }^{34}$, y esmarmotar en Villacarrillo (Jaén) ${ }^{35}$. Fuera de esta área encontramos esporádicamente la forma sin el sufijo -era: en Escúzar, situado a unos $20 \mathrm{~km}$ al suroeste de la ciudad de Granada, quitar la marmota es «desbrozar para que corra el agua», mientras que marmote vale «agua de riego estancada accidentalmente», significado que comparte con la forma marmota que se emplea en Huelma, población jiennense ubicada cerca de la frontera con Granada, y mormote,

31 En Toponimia Prerrománica Hispana, Gredos (Bibl. Rom. Hisp. Estudios y Ensayos 9), Madrid, págs. 59-70.

32 ALEA, mapa 90.

33 Ibidem. Marmotera es aagua de riego estancada accidentalmente» en Topares (Almería) y Pozo Alcón (Jaén); en Galera (Granada) se dice malmotera; en Gor y Huéscar (Granada) es hacer una marmotera; y en Beas de Segura y Peal de Becerro (Jaén) se usa el masc. marmotero.

34 ALEA, mapa 91. Concretamente en La Puebla de Don Fadrique, Huéscar, Galera, Freila y Caniles, todos de Granada; en Galera se recogió la pronunciación malmotera.

35 Ibidem. 


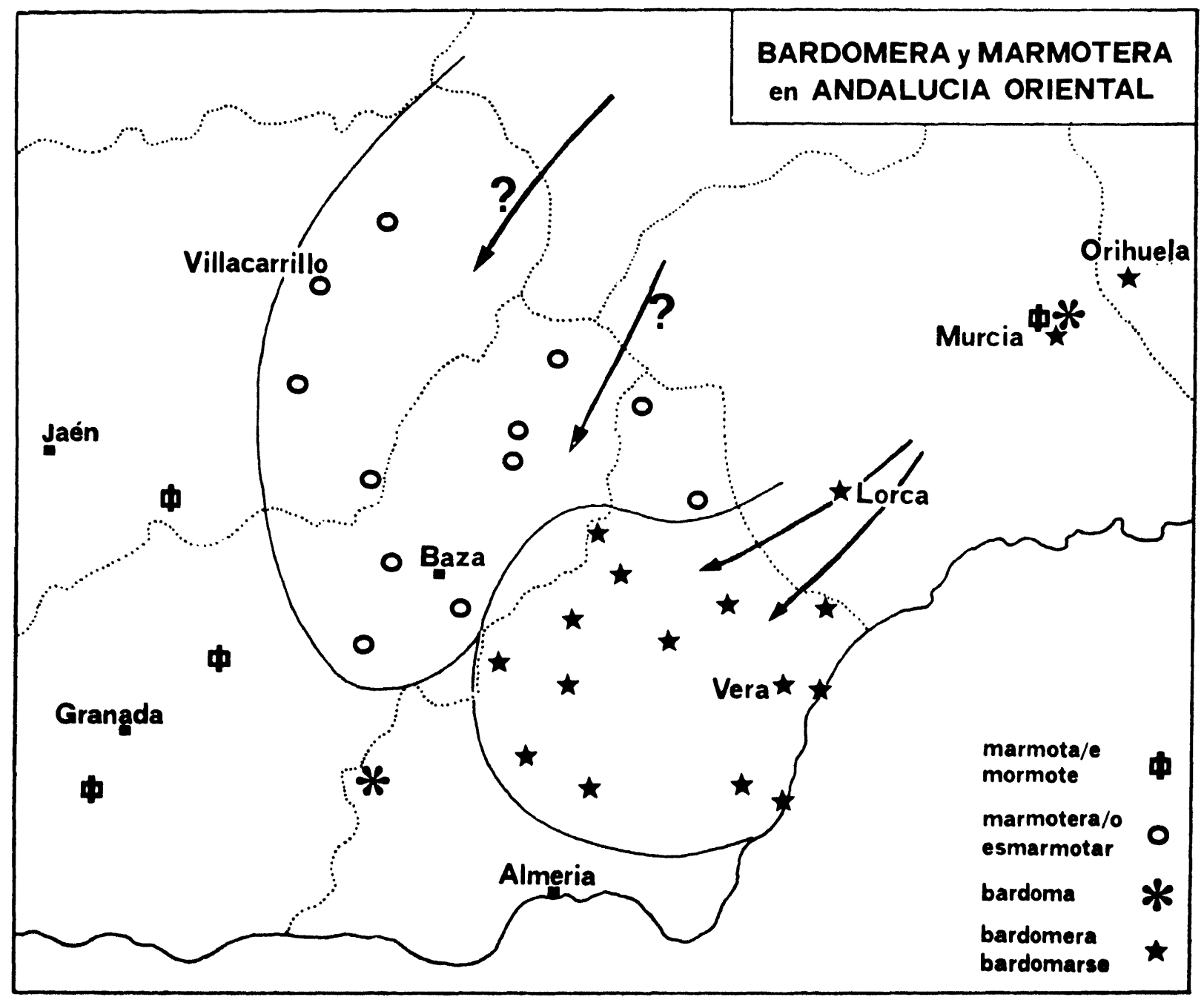

$20 \mathrm{~km}$ al suroeste de la ciudad de Granada, quitar la marmota es «desbrozar para que corra el agua», mientras que marmote vale «agua de riego estancada accidentalmentex, significado que comparte con la forma marmota que se emplea en Huelma, población jiennense ubicada cerca de la frontera con Granada, y mormote, variante recogida en el lugar granadino de Diezma, situado en la sierra a unos $30 \mathrm{~km}$ al noreste de la capital. 
variante recogida en el lugar granadino de Diezma, situado en la sierra a unos $30 \mathrm{~km}$ al noreste de la capital provincial ${ }^{36}$. También nos consta el antiguo empleo de este vocablo en Murcia (1467):

El ryo de Segura que pasa por ante esta çibdad esta ribierto en muchos logares de muchos alamos caydos e marmotas e cañares, de manera que al tienpo de las creçidas del el agua non puede despedir; antes por cabsa de lo susodicho el agua regolfa e por ello la huerta e esta çibdad esta en grand peligro. Por esta rason, que la paresçia quel dicho rio se deuia mandar linpiar ${ }^{37 .}$

Es de destacar, en primer lugar, la gran semejanza que existe en lo semántico entre bardoma y marmota y sus respectivos derivados, detectándose en ambos casos un flujo constante de significado entre: a) 'broza etc. que llevan los ríos, especialmente en crecida'; b) 'tapón que se forma en los cauces por la acumulación de los dichos materiales', y c) 'el agua de riego detenida por la mencionada obstrucción'. Como en el caso de bardoma, la distribución geográfica de las formas y la pertinencia al vocabulario relacionado con el riego, auguran una procedencia árabe donde, de nuevo, parecería tratarse de un participio pasado femenino de la 1.a forma (mal2ū3a de la raíz 1-2-3). De ser así, la primera consonante radical será, con alta probabilidad, una $r$; la segunda $m$ o $b$ por su frecuente alternancia en voces de este origen, sobre todo en la cercanía de otra $m$; y la tercera una de las tres $t$ árabes $(t, t, t)$. En estas circunstancias, lo más indicado es sacar marmota de la ralz R-B-T «atar, sujetar, frenar», cuyo participio pasado femenino marbūṭa significa "atada, sujetada, frenada" e indudablemente, al referirse a una acequia o río, "detenida, obstruida", ya que la VI' forma verbal de esta raíz, tarābaț, de valor morfológico reflexivo, significa «detenerse, estancarse» ${ }^{38}$. De ahí a los significados atestiguados para marmota el desarrollo semántico sería en todo punto idéntico al ya comentado con referencia a bardoma, y no presentaría ninguna dificultad. Tampoco existen impedimentos fonéticos porque, en primer lugar, la $\bar{u}$ se había de pronunciar /o/ en la proximidad de la t enfática: /marbóța/. Luego, la $b$ debía de convertirse en $m$ bajo la influencia asimiladora de la $m$ -

36 ALEA, mapas 90 y 91.

37 Actas Capitulares del Concejo de Murcia: 8-VIII-1467, fol. 27v. García Soriano también halló esta voz en los Discursos Históricos del murciano Francisco Cascales (1621): "Tiene este brazo de río crecientes y inenguantes, y echa las aguas ya turbias, ya claras, y a veces con ramas y marmota, como suelen los ríos grandes en sus avenidas» (op. cit., pág. 81).

38 F. CoRriente, Diccionario Arabe-Español, Instituto Hispano-Arabe de Cultura, Madrid, 1977. 
inicial; es muy improbable que haya interferido en este proceso el nombre del animal porque parece que aún no se empleaba en España en las fechas de nuestra primera documentación de marmota 'bardoma'; sí es posible, por otra parte, que haya influido en combinación con la mencionada asimilación la voz mota "pella de tierra con que se cierra o ataja el paso del agua en una acequia» (Acad.), en vista de la práctica identidad de sentido con una de las tres acepciones de marmota. Las formas granadinas marmote y mormote precisan de una justificación especial porque ni el paso de $-a>-e$ en posición final, ni el de $a>o$ en cualquier posición, son normales en el castellano. El primer fenómeno podría explicarse mediante una etimología paralela masculina marbūt 'atado, obstruido...', pero puesto que se recogió tanto marmota como marmote en Escúzar, y tratándose de voces granadinas, creo que hay que achacar este cambio fonético a la tendencia de convertir toda - $a$ final átona en $-e$, fenómeno que se ha detectado en diversas partes de Andalucía Oriental, y especialmente en El Padul, pueblo situado en el Valle de Lecrín, no lejos de Escúzar ${ }^{39}$. Pero la $o$ que hallamos en vez de $a$ en la forma mormote no tiene explicación dentro del castellano, y es, por lo tanto, necesario suponer que ya tenía esta pronunciación en el dialecto árabe local, y que se trata de un préstamo independiente y paralelo; en apoyo de esta hipótesis está la evidencia de que esporádicamente el hispanoárabe convertía $a$ en $o$ cuando se hallaba en contacto con una consonante velarizadora, que en el presente caso será la $r^{40}$.

Antes de concluir, no podemos dejar sin considerar otra posible etimología para marmot(er)a, pues, teniendo en cuenta el extraordinario parecido que existe entre bardomera y marmotera, así como la idoneidad de la etimología mardūma y -era para la primera, sería razonable preguntarse si marmotera no pudo haber salido del mismo étimo que bardomera, pero con la $2 .^{\mathrm{a}}$ y $3 .^{\mathrm{a}}$ radicales intercambiadas: *marmūda y era. El paso del árabe $d$ al castellano $t$ en posición intervocálica no sería normal, pero tampoco imposible si recordamos casos como almocadén/-tén < al-muquaddam; ataire 'moldura' < al-dā'ira (pron./addá'ira/); atarazana < al-dār al-șánac (pron./addārașsánac/); port. alcatruz, cat. catúfol < al-qādūs. No obstante, esta idea encuentra dos serios obstáculos: a) los ejemplos auténticamente castellanos de $d>t$ parecen

\footnotetext{
39 A. LloRente Maldonado, «Fonética y Fonología Andaluzas», R.F.E., XLV (1962), Madrid, 1964, pág. 233.

10 F. CORRIRNTE, A Grammatical Sketch of the Spanish Arabic Dialect Bundle, Instituto Hispano-Arabe de Cultura, Madrid, 1977, pág. 25, y R. STEIGER, «Contribución a la Fonética del Hispano-Arabe...», Anejo XVII de la R.F.E., Madrid, 1932, página 311.
} 
limitarse a voces cuyo étimo árabe contiene $d d^{41} ;$ y b) es muy improbable que la voz marmota empleada en Huelma (Jaén) y Escúzar (Granada) venga del murciano antiguo marmota porque la influencia murciana no alcanza hasta allí, sino que se tratará de préstamos distintos y paralelos; y en el caso de mormote -empleado en Diezma (Granada) la independencia está asegurada, como ya se ha visto. Entonces, la única manera de explicar la uniformidad de estos derivados a través de una zona tan extensa, sería suponer que en el sureste de la Península la raíz R-D-M se transformó en R-M-D en el árabe dialectal. Pero tal hipótesis se halla en contradicción, por una parte, con la existencia de la forma bardoma en Murcia y Paterna del Río (Almería), donde será voz autóctona derivada de la raíz ortodoxa; $y$, por otra, con el testimonio de los léxicos del árabe granadino y levantino que no atestiguan el empleo de ninguna raíz R-M-D con los significados en cuestión, sino sólo R-D-M ${ }^{42}$. Hay, por lo tanto, que rechazar esta idea.

Queda, no obstante, una incógnita. Mientras que podemos justificar la ausencia de continuidad en la distribución geográfica de las voces bardoma, marmota/-e y mormote, proponiendo que surgen de préstamos independientes tomados directamente del árabe local durante los primeros años de la repoblación cristiana; y tampoco es de difícil interpretación la difusión uniforme de bardomera sobre el territorio almeriense, puesto que tiene un claro foco de origen en Murcia, donde se crearía dicha voz sobre bardoma, cuya antigüedad en estas tierras está confirmada por la documentación medieval; es, sin embargo, más problemática la procedencia de la forma marmotera/-o. Su localización geográfica (ver mapa) en el rincón noreste de la zona cubierta por las encuestas del $A L E A$ apunta hacia una continuidad en tierras albacetenses, y del noroeste murciano. Pero, de hecho, no encontramos ninguna referencia a este vocablo en los estudios de las hablas locales de Albacete y La Mancha, con lo cual el problema ha de permanecer, por el momento, sin solución. Sin duda los futuros Atlas Linguísticos de estas provincias arrojarán nueva luz sobre el asunto, y quizás nos darán una indicación del punto donde aparecerá en los archivos un antiguo marmota, desde el cual se derivó y difundió la voz marmotera/-0 ${ }^{43}$.

41 Ver DCECH s.v. atarazana.

42 El Voc. recoge, bajo el encabezamiento aINPLERE», diversos derivados de la raíz R-D-M, entre ellos el participio pasado mardūm; y P. DE Alcala da el verbo radäm «pisar con pisón».

43 No creo que tengan ninguna relación con esto el arag. marmotear «barbotar», ni balmotadero alégamo, barro pegajoso» empleado en el extremo noreste de Cuencia (ALEANR, mapa 1381), a causa de las diferencias semánticas; los derivados 
La expresión hacer rafa se documenta, y se sigue empleando, como nombre de una de las operaciones de irrigación, en las huertas de Murcia, Lorca y Orihuela, aunque indudablemente se llevará a cabo un procedimiento similar en todos los lugares donde hay riego de acequia, dándosele diversos nombres. Es preciso hacer rafa para regar de una acequia cuando el nivel del agua en el cauce está por debajo del nivel de las tierras que han de ser regadas. En tal caso se hace una parada en la acequia cuyo nivel es insuficiente, delante de la boquera por donde se desea que entre el agua, aguas abajo, para que el agua se acumule o "regolfe» en dicho punto $y$, gracias a esta mayor altura, alcance las tierras en cuestión.

La práctica de hacer rafa siempre se ha considerado perjudicial ya que, por una parte, se impide que el agua llegue a las zonas restantes de la huerta más allá de la obstrucción, y por otra, la construcción de una barrera llena el cauce de escombros, barro o broza, en detrimento de su buen funcionamiento, amén de otros problemas que puede ocasionar. A veces sucedía que los «herederos», o propietarios que se beneficiaban de una acequia, no la mondaran bien, y como consecuencia se llenaba de tierra y vegetación que estorbaba el paso del agua, de manera que sólo haciendo rafa en la acequia mayor podían regar satisfactoriamente sus tierras. Las Ordenanzas de la huerta preveían esta situación:

Porque muchos herederos de las acequias de la huerta de esta Ciudad no han mondado, ni limpiado sus acequias, de manera que el agua no pueda ir por ellas, y à esta causa algunos herederos para regar hazen rafas en las acequias mayores para tomar agua para sus acequias, à causa de lo qual impiden que el agua no passe, y sorriegan los caminos, y hazen otros muchos daños: Por ende ordenaron, y mandaron, que personas algunas no sean osados de hazer rafa en ninguna acequia de las mayores de la huerta, ni poner embaraço ninguno para tomar agua por su acequia si no tuviere la boquera della limpia, y el acequia mondada; y que antes... pida licencia 4 .

(8) 1 ,

de bardoma y marmota siempre mantienen significados muy estrechamente relacionados entre si y con la obstrucción de acequias o ríos.

4 Ordenanzas del Campo y la Huerta de Murcia..., Murcia, 1695; reproducción en offset publicada por la Academia Alfonso X el Sabio, Murcia, 1981, pág. 155. 
Algunas de las acequias más altas tenían el privilegio, al parecer, desde la época musulmana, de poder regar haciendo rafa siempre que las acequias mayores vinieran menguadas de caudal:

las açequias de la Daua et del Turbedal et de Chura 45 et de Alfatego... pueden fazer rafa en las acequias mayores, en tal manera que tomen su derecho del agua et las dichas açequias mayores suban al señal que el agua antes subia que las dichas açequias fuesen menguadas 46 .

En las Ordenanzas de Lorca, además de controlar la práctica de hacer rafa en las acequias, se estipula que estaba prohibido obstruir con paradas las ramblas importantes:

Otrosi, que en las Ramblas principales, è caudalosas, ninguno pueda hazer rafa, sino dexar el agua escueta... ${ }^{47}$.

El concepto es claramente el de 'obstruir un cauce con el fin de acumular agua, para facilitar el riego de tierras altas', cuya definición se adapta perfectamente no sólo a los datos documentales, sino también a su empleo actual en la huerta. En vista de esto, es algo sorprendente encontrar que los diccionarios le atribuyen a la voz rafa un significado bastante distinto. Según la Academia es "cortadura hecha en el quijero de la acequia o brazal a fin de sacar agua para el riego», definición que no ha variado desde que apareció en el Diccionario de Autoridades en 1737, donde se apoya en una cita de las Ordenanzas de Lorca: «A el que hiciere ráfa ò pressa para cazar...mil maravedis repartidos por tercias partes». No obstante, esta documentación no favorece en absoluto su hipótesis acerca del significado, y la expresión «ráfa ò pressa» sólo puede tender a confirmar nuestra definición. La Ordenanza completa reza: «á el que hiziere rafa, ò presa para cazar, è garlito, ò otra manera de presa para pescar, mil maravedis, repartidos por tercias partes... ${ }^{48}$; la idea en el fondo es que se prohibe todo lo que entorpece el libre paso de las aguas. Justo García Soriano, en su Vocabulario del Dialecto Murciano, por otra parte, no hace más que adoptar la definición incorrecta difundida por el Diccionario de la Academia: "Abertura o atajadizo para tomar agua de un cauce" ${ }^{49}$, e incluso José

\footnotetext{
45 Sic por Churra.

46 Ordenanza de 2-V-1363; J. TORREs FontBS, El Regadio Murciano en la Primera Mitad del s. XIV, Junta de Hacendados de la Huerta de Murcia, 1975, pág. 58. (En venta en el Ayuntamiento.)

47 Op. cit., pág. 42.

48 Op. cit., pág. 39.

49 J. Garcia Soriano, op. cit., pág. 106.
} 
Guillén García, tras un admirable trabajo de campo en la huerta de Orihuela, se limita, en su índice, a copiar la definición de García Soriano, a pesar de que los datos que expone en otra sección de su libro demuestran el estado real de las cosas:

El regante la va distribuyendo por el bancal haciendo rafas (enrafar y desenrafar es atajar y destajar respectivamente los pequeños cauces del bancal para dirigir el agua; la operación se efectúa con el legón y se utiliza como material la misma tierra) 50 .

La confusión parece deberse a una falsa etimología que relacionara rafa con raja, y también posiblemente a una interferencia entre tajar «hacer un corte» y atajar «impedir el paso de algo con un obstáculo; por ejemplo del agua de riego para enviarla en otra dirección ${ }^{51}$. En realidad es preciso reconocer que en la situación descrita por este autor la operación de hacer rafa podría llegar a confundirse con la de hacer un corte en el lado del cauce, porque allí precisamente se realizan ambas acciones a la vez, y el regante a menudo hará un portillo en el lado de su bancal para que pueda entrar el agua con mayor holgura al mismo tiempo que obstruye el cauce para detener y desviar el agua. No obstante, esta ambigüedad contextual sólo puede darse cuando se trata de los cauces pequeños que distribuyen el agua de bancal en bancal, pues en cualquier otra circunstancia las Ordenanzas prohíben terminantemente el efectuar cortes en los costados o "quijeros» de las acequias ${ }^{52}$, de modo que hacer rafa ha de ser, en su esencia, el acto de obstruir el cauce, y no el de hacer un corte en su lado.

Eтimologfa. La expresión hacer rafa figura ya en diversos pasajes referentes al regadío de las Hordenanças Antiguas, una recopilación de Ordenanzas establecidas por el Concejo de Murcia durante el siglo XIV, cuya copia debe datar de hacia el año 1400 a juzgar por el tipo de letra y algunos detalles de fonética ${ }^{53}$. Tanto la antiguiedad de la primera documentación como la falta de una etimología romance satisfactoria hacen pensar en un arabismo, sobre todo en vista de que se trata de un término

50 J. Guillén Garcfa, El Habla de Orihuela, «Inst. de Estudios Alicantinos», Serie I, núm. 15, Alicante, 1974, pág. 128.

51 María Moliner, Diccionario de Uso del Español, Gredos, Madrid, 1975.

52 «Art. 53. En los quijeros de las acequias nadie puede abrir portillos, y los que inmediatamente tienen riego de ellas, deben tener sus ventanas o tomas hechas de piedra o ladrillo con su solera, que no esté más baja que la del partidor, y con tablacho de madera y candado (Ordenanzas y Costumbres..., pág. 66.)

53 Conservada en el Archivo Municipal de Murcia, Armario 1, Libro 32. (Parcialmente publicada por J. Torres Fontes. Ver nuestra nota 46.) 
relacionado con el uso de las acequias, mantenidas en gran medida por mudéjares durante toda la Edad Media en Murcia.

A pesar de la incorrección de la definición de rafa que se ha venido manejando, los autores del DCECH recogen esta voz murciana entre las palabras relacionadas con el árabe raff "cornisa» ${ }^{54}$, dejando inexplicado el desarrollo semántico. Si tenemos en cuenta el verdadero significado del término, esta misma etimología disfruta de mayores posibilidades de ser aceptable. Por una parte, hay un parecido conceptual notable entre la idea de una parada que atraviesa la acequia de un lado a otro, y el castellano rafa "la fuerza de cal y ladrillo o piedra que se pone entre tapia y tapia, para la seguridad de la pared", probablemente derivado del nombre de unidad: *raffa, puesto que el verbo árabe raff significa "rodear, ayudar, proteger» ${ }^{55}$. Por otra parte, Pedro de Alcalá da como significado del árabe granadino raff «cañizo de cañas, çarzo de vergas, çarzo de cañas» ${ }^{56}$, lo cual es interesante si recordamos que para construir una parada en una acequia era preciso un cañizo de varas y esparto, alrededor del cual se acumulaba el material de la presa.

Pienso, no obstante, que nuestro vocablo tendrá otro origen. Si la rafa fuera la presa en sí, se hubiera dicho *hacer una rafa igual que encontramos hacer una parada, y quizás hallaríamos la voz rafa empleada en otros contextos en lugar de referirse sólo a la obstrucción que se hace con el fin de levantar el nivel del agua en la acequia, y desviarla en la dirección deseada. El hecho de que se diga siempre hacer rafa sugiere que rafa era una operación y no una cosa. En tales circunstancias es, pues, más verosímil identificar rafa con el nombre de acción árabe rafc 'elevación, levantamiento', puesto que el acto de hacer rafa es precisamente el de hacer una elevación en el nivel del agua de la acequia. La pronunciación normal de raf $^{c}$ en el hispanoárabe sería $/ \mathrm{ráfac}^{c} /{ }^{5}$, de donde sólo se podría esperar rafa en romance ${ }^{58}$.

54 Sub voce rafe $I I$, pág. 753 a6.

55 DCECH sub voce rafe II.

56 PEDRO DE ALCALA, Arte para ligeramente saber la lengua aráviga y Vocabulista ardvigo en lengua castellana, 1505.

57 ARNAld STEIGer, «Contribución a la Fonética del Hispano-Arabe y de los Arabismos en el Ibero-románico y el Siciliano», Anejo XVII de la R.E.F., Madrid, 1932, pág. 90.

58 Esta etimología ya fue esbozada por Dlaz Cassou, que se dio cuenta de la necesidad de relacionar rafa con la ráz árabe $r-f_{-}^{-}$, si bien la transcribió equivocadamente $r$-f-h. (Ver Ordenanzas y Costumbres..., pág. 64, nota 2.) 


\section{TRAGACETE}

La voz tragacete sólo se halla muy escasamente documentada en el castellano medieval, y ya no tenía ningún uso a principios del siglo XVIII cuando se redactó el Diccionario de Autoridades, en cuyo texto se indica que era una «arma arrojadiza de que usaban los moros». En vista de esto, y teniendo en cuenta que el probable sinónimo azagaya tiene origen árabe, lo más conveniente sería buscar asimismo un origen árabe para tragacete. Tal era inicialmente la opinión de Corominas, y en la primera edición de su Diccionario Etimológico ( $D C E C$ ), considera varios posibles étimos, ninguno de los cuales se impone por dificultades fonéticas. La idea que él prefirió entonces, țarf cașa "punta de asta», necesita cinco pasos anormales: la caída de la $f$; la conversión de cayn en gayn; la pronunciación en el hispanoárabe de ā como /e/ en la proximidad de una ș enfática; la agregación de una $-t$ final antietimológica y difícil de justificar (se esperaría más bien -n o $-l$ o $-r$ ); la documentación medieval indica que la $c$ era antiguamente sonora, en cuyo caso debemos buscar un étimo que contenga el sonido árabe $z$. Posteriormente, sobre todo debido al arraigo del vocablo en el vasco actual, donde, además, se encuentran formas emparentadas sin la terminación -ete, cambió de orientación su artículo, y en el $D C E C H$, aunque se mantienen las hipótesis árabes, se considera muy posible un origen vasco para esta voz castellana. En el vasco, no obstante, parece también ser palabra advenediza, y para subsanar esta dificultad busca un último origen en la hipotética raíz indoeuropea *DALGIS 'podadera'. Concluye que la procedencia de tragacete ha de permanecer, por el momento, insegura.

Puede ser orientativo para acercarnos a la verdadera etimología de tragacete, la observación de que nuestro vocablo siempre, o casi siempre, se usaba en plural en el castellano medieval ${ }^{59}$. Así, tratándose de una arma que por su naturaleza se solía nombrar en plural, no sería sorprendente que el préstamo se hubiera tomado de la forma del plural en la lengua de origen, lo cual encajaría perfectamente con que la terminación -ete fuera el sufijo árabe - $\bar{a} t$ que marca el plural de las voces femeninas terminadas en - $a$. Hemos de buscar, entonces, una forma árabe *tragaza, o algo similar, con la $z$ sonora por el motivo indicado más arriba. En la mayoría de los casos, las raíces árabes sólo contienen tres consonantes fundamentales o radicales, que aquí deben de ser $r$-g- $z$, puesto que la $t$

59 Ver los ejemplos citados en el DCECH s.v. 
es la única que puede ser servil, es decir empleada en la derivación mortológica. Pero, desafortunadamente, no hay ninguna raíz $r-g-z$. No obstante, la raíz g-r-z "pinchar, clavar" sería idónea, y en efecto el nombre de acción de la $\mathrm{II}^{\mathrm{a}}$ forma, tagriz, tiene, entre otros significados, el de "estaca" ${ }^{0}$. De ahí se pudo formar un nombre de unidad *tagriza, cuyo plural *tagrīzāt, "pinchos, estacas» proporciona una excelente etimología para tragacete. En la pronunciación normal hispanoárabe esta palabra sonaría /tagrezét/ porque la $\bar{i}$ en la vecindad de una $r$ se diría /e/, y la $\bar{a}$ entre $z$ y $t$ se convertiría asimismo en /e/, conforme con las características de la imela en este dialecto. Ni el traslado de la $r$ explosiva agrupada a la primera sílaba, ni la conversión de la $e$ átona interna en /a/ ofrecen ninguna dificultad, pues ambos fenómenos son relacionables con tendencias bien documentadas en la historia de la lengua castellana ${ }^{61}$ : *tagrezét $>{ }^{*}$ traguezét $>$ tragazet $(e)$.

Si aceptamos esta etimología árabe para la voz castellana, entonces ¿qué explicación pueden tener las formas vascas? La coincidencia entre los significados hace difícil creer que el parecido formal sea puramente casual, y que tengan otro origen. Pero, por otra parte, en la segunda mitad del siglo XIII, único período para el cual tenemos firmes pruebas documentales del empleo de esta arma en el ámbito castellano ${ }^{62}$, la frontera con los moros se hallaba ya muy lejos del País Vasco, y sería sorprendente que llegaran hasta allí noticias de una lanza ligera que solamente empleaban los musulmanes, y que, al parecer, se hizo obsoleta después de un breve espacio de tiempo. No obstante, a pesar de la afirmación del Diccionario de Autoridades de que el tragacete era solamente empleado por los moros, y aunque en una de las citas recogidas por el $D C E C H$ consta que los cristianos en cuestión no sabían manejar con provecho esta arma ${ }^{63}$, sin embargo un pasaje del Libro del Repartimiento de Murcia deja fuera de duda que al menos algunos caballeros cristianos

60 Francisco Corriente, Diccionario Arabe-Español, Instituto Hispano-Arabe de Cultura, Madrid, 1977, pág. 552.

61 Los siguientes ejemplos demuestran la movilidad de la $r$ explosiva agrupada: prenda del ant. pendra, peñdra, lat. PIGNORA; quebrar de CREPARE; cotofre «vasija» de cotofre; cocodrilo del lat. CROcodilus; etc. Los casos de alternancia entre a/e, $\mathrm{e} / \mathrm{i}, \mathrm{y} \mathrm{o} / \mathrm{u}$ en posición átona interna abundan en los léxicos del castellano antiguo y dialectal.

62 El Diccionario de Autoridades cita de la Crónica General de Florián de Ocampo, escrita en la primera mitad del siglo XVI, pero este autor tomó sus datos de obras de Alfonso $X$ el Sabio, nuestra mejor fuente para tragacete.

63 aLos moros los cercaron de todas partes, tirándolos sus tragazetes et sus azagayas... pero fueron los cristianos acordados en esto: quantas azagayas et tragazetes les tiravan, todas las quebrantavan, que una no les enbiavan dellas; et fue una cosa que les guaresçió mucho* (1."Crónica General). 
tenían tragacetes entre sus armas. Con referencia a un tal Ladrón, dice un testigo:

... un poco antes que el rey uiniesse, que enuio aqui caudallo et armas et xii azonas ${ }^{64}$ et tragaçetes et balestas 65 .

Ahora, otro testigo, describiendo las mismas armas, dice: «et $\mathbf{x}$ azconas munteras et xii alauesas et quatro balestas», y otro: «fasta a xii azconas" ${ }^{66}$. De esto hay que concluir que había escasas diferencias entre la azcona, la alavesa y el tragacete. La primera de estas armas era de procedencia vasca, y la segunda también, según se desprende de su nombre; indudablemente el País Vasco era en la Edad Media un centro de producción de la lanza ligera. Así no tendría nada de extraño que, puesto de moda el tragacete como variante de la azcona o alavesa, los artesanos vascos se hubieran lanzado a la producción de dicha arma, aprovechando toda su experiencia en el arte, para satisfacer la demanda de este nuevo artículo. De este modo el vocablo tragacete entraría en el vasco en el siglo xIII, desarrollándose posteriormente las demás formas emparentadas.

\section{RoBert Pocklington}

\footnotetext{
64 Sic por «azconas».

65 Edición de J. Torres Fontes, C.S.I.C. Escuela de Estudios Medievales, Academia "Alfonso X el Sabio», Madrid, 1960, pág. 227.

66 Ibidem.
} 